\title{
Sustainability of Quality Improvement Initiatives within the Saudi Ministry of Health Hospitals: An Institutional Overview
}

\author{
Salem Alasmari ${ }^{a}$ Sharon Williams ${ }^{b}$ Nicholas Rich ${ }^{c}$ David Rea $^{d}$ \\ aMinistry of Health, Abha, Saudi Arabia; bSwansea Centre for Improvement \& Innovation, College of Human \& \\ Health Sciences, Swansea University, Swansea, UK; ' School of Management, Swansea University, Swansea, UK; \\ ${ }^{\mathrm{d} D e p a r t m e n t}$ of Public Health, Policy, and Social Sciences, College of Human \& Health Sciences, Swansea University, \\ Swansea, UK
}

\section{Keywords}

Sustainability · Quality improvement · Institutional theory

\begin{abstract}
Background: The failure of quality improvement projects has been a global issue that exists within different geographical and organisational contexts. The case of this in the healthcare sector is more obvious, given the complex and contingent characteristics of healthcare organisations. For this reason, healthcare settings require more deliberate thought and extensive efforts to sustain the gains of quality improvement. Within the context of Saudi Arabia, the Ministry of Health $(\mathrm{MOH})$ has long been introducing a number of improvement initiatives and quality accreditation projects to improve hospitals' performance. These efforts represent precious investments that are supposed to sustain and flourish over time. Summary: The sustainability of the improvement initiatives within the $\mathrm{MOH}$ hospitals is still the main struggle. This challenge requires a more holistic analysis that exceeds hospitals' boundaries by considering the external influences that undermine the capability of these hospitals to sustain the improvement. The institutional environment is one of the most critical dimensions that need to be ex-
\end{abstract}

karger@karger.com www.karger.com/sjh

Karger $\stackrel{\text { ' }}{5}$

GOPEN ACCESS
(C) 2021 The Author(s)

Published by S. Karger AG, Basel

This article is licensed under the Creative Commons AttributionNonCommercial-NoDerivatives 4.0 International License (CC BYNC-ND) (http://www.karger.com/Services/OpenAccessLicense) Usage and distribution for commercial purposes as well as any distribution of modified material requires written permission. plored prior to implementing quality improvement initiatives. Understanding the institutional characteristics provides significant overview of the regulatory powers that affect the implementation of quality improvement initiatives within healthcare organisations. Key Messages: An institutional perspective has been employed in this study to provide an overview of the external institutional influences that affect the sustainability of improvement initiatives. This study establishes a baseline for further debate on the mediating role of the institutional powers in determining the sustainability level of quality improvement initiatives within the healthcare sector.

(C) 2021 The Author(s)

Published by S. Karger AG, Basel

\section{Introduction}

Improvement sustainability involves maintaining the gains of the implemented improvement initiatives [1], which leads to a state of organisational acceptance and implementation. This allows newly introduced practices to prosper for the aim of continuous improvement [2]. Drawing on this, sustainability is perceived as a compre- 
hensive concept to describe the dynamic and continuous efforts that are necessary for maintaining the achieved improvement results without which the improvement projects become just a waste of resources due to what has been described as "improvement effect evaporation" [3]. Therefore, sustaining the improvement initiatives has become a burning issue among both researchers and executives within the field of quality improvement.

Phillip Crosby stated in his seminal work Quality Is Free that $>90 \%$ of quality improvement initiatives failed in the USA [4]. Similarly, the renowned change authors Beer and Nohria [5] described the change failure among different sectors in the USA as a "brutal fact." At the global level, a comprehensive survey, conducted by McKinsey and company using over 3,000 executives from different global industries around the world, revealed that only a third of participants stated that their organisations succeeded in achieving the performance improvement level they had aimed for. Other antecedents about quality improvement failure have been identified in different industries and areas of the world [6]. Aside from the contrasting interpretations of improvement failure, increasing concerns about the sustainability of quality improvement efforts prompt further understanding of the complexity of this domain. This requires broadening the debate beyond an organisation's boundaries by considering the contextual influences that may hinder and or encourage the level of improvement capability, especially within public healthcare organisations.

Public healthcare organisations are viewed as complex entities, given their contextual conditions such as interdependent networks, political influence, and bureaucratic structure [7]. This complexity is a critical determinant for selecting the proper mechanism by which the improvement can be achieved [8]. Burnes [6] pointed out the necessity of gaining further understanding about organisations in order to explore the how and why aspects of improvement including an organisation's structure, management, and behaviour. Moreover, Berwick [9] stated that quality improvement is a "system property" that requires changing the system to achieve better results. This means that a system-wide implementation of improvement initiatives needs to be considered in relation to the whole context of healthcare organisations to ensure successful and sustainable improvement. Thus, a more holistic approach is required, given the complex nature of healthcare settings. In keeping with this view, the principles of the general systems theory draw attention to the wider context within which organisations exist [10]. According to this, organisations are viewed as rational enti- ties [6] and living organisms that must be adapted to their institutional environment to survive [11] and sustain the achieved improvement. The institutional environment represents the exogenous normative and regulatory powers that shape and constrain the policies and actions of organisations [12]. This draws further attention to the mediating role of the institutional environment to which healthcare organisations belong in determining the sustainability level of quality improvement initiatives. Thus, the institutional perspective in this study is a starting point from which further sustainability lessons can be learnt from within the Saudi healthcare context. In other words, this study sheds new light on the use of an institutional lens for analysing the contextual impact on the sustainability of quality improvement initiatives within the public healthcare sector.

\section{Quality Improvement within the Saudi Healthcare Context}

The history of quality improvement within the Saudi Ministry of Health (MOH) dates back to the 1990s, upon the establishment of the National Committee on Quality Assurance in primary healthcare services $[13,14]$. These efforts were accompanied by increased quality awareness at the national level that culminated with the establishment of the King Abdulaziz Quality Award in 1999 [15]. The aim of this award was to encourage private and public sectors to achieve high-quality performance including healthcare services. Despite the strong government commitment to improve healthcare quality, the Saudi healthcare system has been struggling with various challenges such as medical errors, long waiting times, and low quality of services [16]. With these critical challenges in mind, the healthcare system experiences suboptimal performance, despite the huge expenditure.

The largest actor in the Saudi healthcare system is the Ministry of Health [17]. So, it is significant that it has recently assigned a deputy minister for planning and organisational excellence with the aim of building distinctive capabilities that can accelerate the improvement process and achieve high quality standards [18]. Accordingly, several improvement initiatives have been introduced into the $\mathrm{MOH}$ hospitals between the period 2009 and $2018[19,20]$.

However, given that the improvement initiatives are expected to be sustained as a new way of working [1], the evergreen question is to what extent the implemented improvement initiatives are sustained? Answering this ques- 
tion requires a more holistic approach that goes beyond the content of improvement by shedding light on the context within which the improvement initiatives take place. Thus, exploring the institutional configuration of the $\mathrm{MOH}$ hospitals provides further understanding about the mechanism by which the quality improvement initiatives are being adopted and sustained. This implies further consideration of the institutional powers that interact with the internal environment of the hospitals and shape their capability in adopting and sustaining the quality improvement initiatives.

\section{Institutional Framework of the $\mathrm{MOH}$}

The $\mathrm{MOH}$ delivers about $60 \%$ of healthcare services in Saudi Arabia [21, 22]. Such a wide scope of service requires substantial operational expenses. Around SAR 83, 766, 424 billion was allocated to the $\mathrm{MOH}$ budget in 2017 to cover healthcare services [20]. This is an inevitable consequence of the expanded structure of the $\mathrm{MOH}$ as a "large-scaled institution" that maintains free access to most healthcare services for all Saudi nationals.

The $\mathrm{MOH}$ is committed to providing curative and preventive healthcare services [18]. A centralised hierarchy that contains multiple layers of management governs the 2 domains of healthcare services. The central structure of the $\mathrm{MOH}$ identifies its responsibility for setting strategic plans, establishing healthcare policies, and overseeing healthcare programmes, in addition to controlling and monitoring other healthcare services [17]. This centralised structure integrates a broad network of healthcare services dispersed over 13 governorates with diverse geographic and socioeconomic characteristics.

A directorate of health affairs [23] manages the healthcare services in each of the 13 governorates. The central body of the $\mathrm{MOH}$ plays the decisive role in allocating and determining most of the resources and the strategic decisions of these directorates. For instance, article 8 of the internal $\mathrm{MOH}$ by-laws states that the provincial healthcare directorates are responsible for executing all plans and programmes set by the $\mathrm{MOH}$ [24]. This reflects the functional role of these directorates, as being executive bodies with limited authority. The health directorates work collaboratively with the central body of the $\mathrm{MOH}$ to oversee preventive and therapeutic healthcare services. These services are delivered via various healthcare settings, such as hospitals, primary healthcare centres (PHCs), and other specialised medical centres, located in different cities and villages in each province.

The provincial healthcare services are delivered at primary, secondary, and tertiary levels [14]. The primary

Sustainability of Quality Improvement Initiatives within the Saudi MOH level is composed of PHCs that work as gatekeepers by providing preventive and curative healthcare services and referring cases that require further management to secondary or tertiary levels [21-23]. These service levels are delivered via a broad network of healthcare facilities distributed among different catchment areas. This network includes 2,261 PHCs, in addition to 286 general and tertiary hospitals with a total capacity of 44,665 inpatient beds [20]. There are a total of 256,604 employees in different healthcare and administrative specialities. This network of healthcare organisations represents the institutional framework within which the $\mathrm{MOH}$ operates. Such a wide healthcare network is being managed and controlled by a highly centralised governance structure.

\section{Improvement Efforts within the MOH Hospitals}

Derived by the national transformation plan Vision 2030, the healthcare sector in Saudi Arabia is on the brink of structural change. This plan is being sponsored by the top political leaders in the country who are highly committed to achieving its objectives. The healthcare sector is actively participating in Vision 2030. A theme called "Caring for our Health" represents one of the milestones of the vibrant society theme. This theme includes various strategic goals aimed at improving social and healthcare services in both public and private sectors. The vision sets a major goal of increasing the average life expectancy from 74 to 80 years as an ultimate outcome of various healthcare improvement programs. The vision also requires the public and private healthcare sectors to improve the quality and efficiency of the organisations [25].

In response to Vision 2030, several administrative and medical improvement initiatives have been implemented within the MOH hospitals $[19,20]$. Some corporate improvement methodologies have been adopted in order to implement initiatives that aim at improving the quality of services in the $\mathrm{MOH}$ hospitals [26]. These methodologies include TQM, Lean, Six Sigma, and Lean Six Sigma that have mainly been adapted to improve the workflow in certain departments such as operation rooms and outpatient and inpatient wards $[26,27]$. These initiatives achieved remarkable success upon their introduction and were considered effective tools to improve service quality within a number of $\mathrm{MOH}$ hospitals across the country.

In parallel, the $\mathrm{MOH}$ has intensified its efforts to pursuing accreditation for its hospitals. Seeking accreditation is based on the idea that compliance with evidence-based standards will lead to high levels of service quality within a safe work environment [28]. Thus, the accreditation programmes have been introduced as leverage for quality 
improvement within the $\mathrm{MOH}$ hospitals. A national accreditation body named the Central Board for Accreditation of Healthcare Institutions (CBAHI) was established to maintain continuous compliance of healthcare facilities with the standards of quality and patient safety [29]. It also aims to assess the quality of healthcare services based on predetermined quality standards.

By and large, the main question about the implemented quality improvement initiatives including the accreditation programmes is to what extent they are sustained over time in a way that benefits the overall quality of healthcare outcomes and support the healthcare transformation strategy. The following institutional analysis provides further understanding as to the extent to which these initiatives are implemented and sustained within the $\mathrm{MOH}$ hospitals.

\section{Analysis of Institutional Barriers to Sustain Quality Improvement Initiatives}

To provide further analysis of the institutional barriers, it is necessary to draw attention to the potential conflict between the institutional and contingency theories [30]. This is attributed to the contrasting assumptions that underpin each theory in dealing with the improvement initiatives. The main assumption of the contingency theory revolves around an organisation's ability to fit its internal characteristics with external contingencies in order to achieve high performance [31, 32]. Meanwhile, the institutional theory implies that an organisation needs to adopt legitimacy to garner support [30]. Legitimacy is achieved when an organisation conforms to the rules and requirements of its institutional environment [33, 34].

Within the improvement context, the institutional principles suggest that organisations embrace improvement initiatives to support their legitimacy that can lead to increasing their chances to survive [35]. Unlike the contingency theory, the institutional theory has been criticised for its emphasis on conformance and legitimacy, rather than achieving real organisational effectiveness [36]. The current governance structure of the $\mathrm{MOH}$ reflects one of the negative impacts of conformance and legitimacy powers on sustaining the quality improvement initiatives. The government regulations and the MOH's top-down hierarchy represent major institutional powers that dominate over hospitals. The consequences of these institutional powers are presented in the following dimensions.

\section{Centralised Governance}

The widespread network of MOH hospitals is governed by a centralised organisational hierarchy [17-39] that relies on coercive isomorphic power [40] in which organisational structures including policies, routines, values, and regulations are embedded to form general principles that guide organisations' behaviours [41]. These institutional elements are being imposed on organisations without much consideration to the quality aspects of the work at hand [36]. This perspective sacrifices effectiveness at the expense of achieving formality. The current implementation mechanism of the quality improvement initiatives within the $\mathrm{MOH}$ hospitals provides an illustrative example of this situation.

The centralised governance of the $\mathrm{MOH}$ is beset with various operational challenges that undermine the quality of the delivered healthcare services. These include increasing challenges in terms of medical errors, long waiting times, low service quality [16] as well as low bed availability, and poor utilisation rates [22-42]. Recent $\mathrm{MOH}$ statistics show low hospital bed coverage of 13.2 beds per 10,000 people, accompanied by a low occupancy rate of $60 \%$ of the available beds [20]. These facts also question the effectiveness of the improvement efforts that have been exerted by the $\mathrm{MOH}$ to improve hospital performance.

Hassanain et al. [26] reported their findings on one clinical improvement initiative that adapted lean methodology. The initiative, named surgical pathway improvement, aimed at improving the utilisation and patient flow in operation rooms in different $\mathrm{MOH}$ hospitals across the country. It has been reported that one-third of the hospitals that implemented these initiatives have failed to achieve the expected performance. Another assessment study by Hassanain et al. [43] reported the failure of establishing performance improvement units in applying lean 6 sigma and change management methodologies across 13 governorates. It has been stated that the established performance improvement units have dropped back to the baseline level after 9 months of their establishment. This failure was attributed to the low level of sustainability of this initiative as it was successfully implemented in the beginning, yet it required further commitment, empowerment, and training of the team members to sustain its early success.

\section{Top-Down Approach to Improvement Initiatives}

The quality improvement initiatives are imposed using a top-down approach where the provincial healthcare settings including hospitals are obliged to implement 
them. Such a unilateral improvement approach does not pay attention to the contextual variations and health indicators according to which the unique improvement needs are identified for each province and worked upon accordingly. This approach contradicts the contextual variations between the $\mathrm{MOH}$ hospitals that are located over wide geographical areas. The household health survey of 2017 revealed significant variations between provinces in different indicators of health status and the prevalence of, for example, smoking, road traffic accidents, cancer, and chronic diseases [44]. There are also inconsistent levels of quality of the delivered healthcare service and an unequal distribution of healthcare services and professionals across the provinces [45]. Thus, the $\mathrm{MOH}$ facilities vary from one province to another in terms of their technical and scale efficiency (inputs compared to outputs) [46]. These aspects question the effectiveness of the current coercive imposition of the quality improvement initiatives on the $\mathrm{MOH}$ hospitals that face diverse challenges.

Under the coercive imposition of improvement initiatives, hospitals are required to conform to the rules and requirements of the $\mathrm{MOH}$ regulations and CBAHI standards, aside from the quality aspects of the work at hand $[33,34]$. Reflecting on these facts and bearing in mind the current mandatory mechanism of quality improvement initiatives, the $\mathrm{MOH}$ hospitals tend to apply quality improvement initiatives for legitimacy and formality purposes, rather than achieving service improvement. In this case, the $\mathrm{MOH}$ hospitals implement the quality improvement initiatives mainly to conform to the top regulatory bodies with less attention to their real improvement outcomes. Dealing effectively with these challenges would require a decentralised governance model to provide autonomy and internal capability for the $\mathrm{MOH}$ hospitals. This would offer better adaptability based on the contingency principles where hospitals can identify and introduce the improvement initiatives that fit their specific contingencies.

\section{Compulsory Accreditation Schemes}

The CBAHI accreditation has become a mandatory programme in Saudi Arabia where all public and private healthcare institutions are obliged to fulfil its requirements [28]. Such compulsory accreditation contrasts with most of the international accreditation programmes $[47,48]$ that are set as a voluntary continuous improvement framework. Under new regulations issued by the Saudi Council of Ministers in 2013, the accreditation became mandatory for all $\mathrm{MOH}$ hospitals as a prerequisite for the renewal of their operation licences [29]. Accordingly, the accreditation programmes became national programmes that represent additional coercive regulatory power that impact the $\mathrm{MOH}$ hospitals.

By comparing the voluntary and coercive approaches of accreditation, variation has been identified in terms of their improvement outcomes. Drawing on an extensive range of international sources, Alkhenizan and Shaw [49] in their systematic review reported consistent evidence on the positive association between a number of voluntary international accreditation programmes and healthcare service improvement across the literature. This included different clinical practices such as ambulatory surgical care, trauma, myocardial infarction, infection control, and pain management.

On the contrary, there is a lack of empirical evidence about the positive impact of the current coercive accreditation projects on hospital quality within the Saudi context. Alasmari [50] recently conducted a comparative review of 42 quality-of-care indicators in $88 \mathrm{MOH}$ hospitals. Remarkably, the study revealed that the nonaccredited hospitals outperform the accredited hospitals by achieving better quality indicators. In a similar vein, Almasabi and Thomas [28] conducted a study of over 669 employees and 12 senior managers working in $3 \mathrm{MOH}$-accredited hospitals. The study revealed that the accreditation did not impact the quality indicators in the hospitals under review and that no monitoring mechanism has been set to assess basic outcomes.

The variation between the outcomes of the national and international accreditation projects questions the usefulness of the coercive approach where the accreditation became a government regulatory tool. This contradicts the normative role of the accreditation programmes as a non-governmental body that contribute towards promulgating professional standards $[10-49,51]$. Such a mandatory approach represents a form of coercive institutional power where hospitals are required to adhere to a list of centrally imposed standards without considering the contextual variations between these hospitals such as the scope of service, bed capacity, or infrastructure. These contingencies are important determinants that need to be considered prior to introducing accreditation projects. Understanding these contingencies and effectively interacting with them must be accompanied by a certain level of hospital autonomy that can support their capabilities to adapt and sustain the accreditation projects.
Sustainability of Quality Improvement Initiatives within the Saudi MOH
Saudi J Health Syst Res 2021;1:3-10 DOI: $10.1159 / 000514179$ 


\section{Research Proposition for Adopting an Institutional Perspective}

This article has shed light on the use of an institutional lens for analysing the contextual impact on the sustainability of quality improvement initiatives within the public healthcare sector. This perspective has long been applied to understand a wide range of organisational reforms and change initiatives [52]. It suggests that organisations embrace change initiatives to support their legitimacy that can lead to increasing their chances to survive [35]. This legitimacy is achieved when an organisation conforms to the rules and requirements of its institutional environment $[33,34]$. This conformance is described as "the degree of compliance by an organisation with the organisational form of structures, routines, and systems prescribed by institutional norms" [53].

The institutional environment represents a group of networked and homogeneous organisations that share similar characteristics. The legitimacy of an organisation to fit the institutional environment is influenced by the institutional isomorphic change that forces an organisation to resemble other organisations where it operates. This change may take different forces, i.e., coercive, mimetic, or normative [40]. Each of these forces has an influential impact on how an organisation fits within its institutional environment. Thus, understanding these forces provides useful analysis framework for service organisations, like healthcare settings, as to how improvement efforts are being institutionalised.

Generally, the service improvement literature has focussed on back office and routine work processes [54], yet healthcare has different environmental aspects that need to be considered in relation to improvement projects. The attention afforded to healthcare improvement is a recent phenomenon, and health care is a complex system which poses many challenges to the basic set of enablers and success factors $[55,56]$. The healthcare sector operates with a network of different actors [57] and cannot be improved by individuals or elites alone [9]. It has been suggested that the understanding of the context around healthcare quality improvement is based on the complexity of improvement as well as the diversity of healthcare organisations where prescriptive methods for managing improvement are unlikely to succeed [58].

Such a complex and interdependent context represents a unique environment with multiple institutional powers. Although extensive research has been carried out on different contextual conditions of improvement [5860 ], to the best of our knowledge, no research has been found that adopts an institutional lens in analysing the improvement context and its impact on the sustainability of quality improvement initiatives within the healthcare sector. Therefore, this overview establishes a baseline for further debate on the mediating role of institutional powers in determining the sustainability level of quality improvement initiatives within the healthcare sector.

\section{Conclusion and Recommendations}

This overview gives an account of the institutional environment within which the $\mathrm{MOH}$ hospitals exist. Such an environment represents the external regulatory powers that shape and constrain the quality improvement initiatives within these hospitals and play a decisive role in their adoption and sustainability. The $\mathrm{MOH}$ is governed by a central organisational structure that includes an overwhelming number of healthcare settings that deliver multifaceted healthcare services. These services are spread over a number of provinces with varying socio-demographic characteristics. The current bureaucratic governance does not support the implementation of quality improvement initiatives within the dispersed $\mathrm{MOH}$ facilities. The limited autonomy and scope of authority offered to these healthcare settings including hospitals lessen their capability to adopt and sustain the improvement initiatives. Likewise, these hospitals struggle with sustaining the outcomes of quality accreditation projects due to the mandatory implementation approach the does not pay much attention to the contextual variations between hospitals.

Accordingly, the institutional perspective is expected to provide an effective analysis framework that can be used for both scientific and applied research to study the institutional powers that affect the adoption and sustainability of the quality improvement initiatives within the healthcare context in general. The top-down improvement approach as well as the centralised governance and less autonomy offered to the $\mathrm{MOH}$ hospitals represent public policy challenges that need to be taken aboard to support the improvement capability of these hospitals. These issues represent public policy challenges that require deliberate assessment from a macro-level perspective. In other words, further attention needs to be paid by the people in charge of the healthcare transformation strategy when establishing the new models of care. Moreover, the role of mandatory accreditation in supporting the improvement capability of the $\mathrm{MOH}$ hospitals needs further assessment in terms of its sustainable outcomes. 


\section{Acknowledgments}

We gratefully thank the General Department of Research and Studies at the Ministry of Health in Saudi Arabia for facilitating access to some information that was used in this paper.

\section{Conflict of Interest Statement}

The authors declare that they have no conflict of interest.

\section{Funding Sources}

This paper is part of the first author's doctoral research, supported by the government of Saudi Arabia.

\section{Author Contributions}

This paper is part of a $\mathrm{PhD}$ research. The manuscript was designed and written by Salem Alasmari. Sharon Williams, Nick Rich, and David Rea, as PhD supervisors, contributed to revising and editing the manuscript.

\section{References}

1 Silver SA, McQuillan R, Harel Z, Weizman AV, Thomas A, Nesrallah G, et al. How to sustain change and support continuous quality improvement. Clin J Am Soc Nephrol. 2016 May 6;11(5):916-24.

2 Radnor ZJ. Review of business process improvement methodologies in public services. London: Aim Research; 2010.

3 Sustainability NH. Its relationship with spread and adoption, General improvement skills. Coventry, UK: Improvement Leaders' Guide; 2007.

4 Crosby PB. Quality is free: the art of making quality certain. New York: McGraw-Hill; 1979.

5 Beer M, Nohria N. Cracking the code of change. Harv Bus Rev. 2000 May 1;78(3):133216.

6 Burnes B. Managing change: a strategic approach to organisational dynamics. Pearson Education; 2009.

7 Rojas D, Seghieri C, Nuti S. Organizational climate: comparing private and public hospitals within professional roles. Suma De Negocios. 2014 Jan 1;5(11):10-4.

8 Granville G. What does the service improvement literature tell us and how can it make a difference to implementation. Gilliangranville Associates On-Line Report; 2006. p. 61520.

9 Berwick DM. Improvement, trust, and the healthcare workforce. Qual Saf Health Care. 2003;12(Suppl 1):i2.

10 Scott WR, Ruef M, Mendel PJ, Caronna CA. Institutional change and healthcare organizations: from professional dominance to managed care. University of Chicago Press; 2000.

11 Morgan G. Images of organization. 2006.

12 Wade JB, Swaminathan A. Institutional Environment. The Palgrave Encyclopedia of Strategic Management. Available from: http:// www.palgraveconnect.com/esm/doifinder/ 10.1057/9781137294678.0316. Accessed July $21,2015$.

13 Al-Abdul-Gader AH. Managing computer based information systems in developing countries: a cultural perspective. IGI Global; 1999.
14 Albejaidi FM. Healthcare system in Saudi Arabia: an analysis of structure, total quality management and future challenges. J Alt Perspect Soc Sci. 2010;2(2):794-818.

15 Saudi Standards, Metrology and Quality Organization [Internet]. Saso.gov.sa. 2019 [cited 2019 Jun 17]. Available from: https://www. saso.gov.sa/en/pages/default.aspx.

16 Alrabeah A, Ogden SM, Edgar DA, Fryer KJ. TQM in the Saudi Health care system: a national cultural perspective. World Rev Bus Res. 2015;5(2):120-36.

17 Al Yousuf M, Akerele TM, Al Mazrou YY. Organization of the Saudi health system.

18 Ministry of Health [Internet]. Moh.gov.sa. 2019 [cited 2019 Jun 25]. Available from: https: //www.moh.gov.sa/en/Pages/default. aspx.

19 Ministry of Health Achievements. [Internet]. Moh.gov.sa. 2019 [cited 2019 Jun 17]. Available from: https://www.moh.gov.sa/Ministry/About/Pages/AchievementsStatistics. aspx.

20 Annual Statistical Book [Internet]. Ministry of Health; 1440 [cited 2020 Nov 28]. Available from: https://www.moh.gov.sa/en/Ministry/ Statistics/book/Pages/default.aspx.

21 Almalki M, FitzGerald G, Clark M. Health care system in Saudi Arabia: an overview.

22 Alkhamis AA. Critical analysis and review of the literature on healthcare privatization and its association with access to medical care in Saudi Arabia. J Infect Public Health. 2017 May 1;10(3):258-68.

23 Walston S, Al-Harbi Y, Al-Omar B. The changing face of healthcare in Saudi Arabia. Ann Saudi Med. 2008 Jul;28(4):243-50.

24 Bylaws of National Healthcare System 2003 [Internet]. Moh.gov.sa. 2019 [cited 2019 Jun 19]. Available from: https://www.moh.gov. sa/Ministry/Rules/Pages/default.aspx.

25 Saudi Arabia Vision 2030. Vision 2030. Accessed 2019 Oct 21. Available from: https:// vision2030.gov.sa/en.

26 Hassanain M. An overview of the performance improvement initiatives by the ministry of Health in the Kingdom of Saudi Arabia. Inquiry. 2017 May 10;54:0046958017707872.
27 Al Owad A, Samaranayake P, Karim A, Ahsan $\mathrm{KB}$. An integrated lean methodology for improving patient flow in an emergency department: case study of a Saudi Arabian hospital. Prod Plan Control. 2018 Oct 3;29(13):1058-81.

28 Almasabi M, Thomas S. The impact of Saudi hospital accreditation on quality of care: a mixed methods study. Int J Health Plann Manage. 2017 Oct;32(4):e261-78.

29 Saudi Central Board for Accreditation of Healthcare Institutions [Internet]. Cbahi.gov. sa. 2019 [cited 2019 Jun 19]. Available from: https://www.cbahi.gov.sa/surveyor/AboutUs. aspx.

30 Donaldson L. The contingency theory of organizational design: challenges and opportunities. In: Organization design. Boston, MA: Springer; 2006. p. 19-40.

31 Donaldson L. The contingency theory of organizations. Sage; 2001 Feb 20.

32 Child J. Managerial and organizational factors associated with company performance part I. J Manag Stud. 1974 Oct;11(3):175-89.

33 Parsons T. Suggestions for a sociological approach to the Theory of Organizations: I. Adm Sci Q. 1956 Jun 1;1(1):63-35.

34 Scott WR. Institutions and organizations: ideas, interests, and identities. Sage Publications; 2013 Jul 24.

35 Dawson P, Andriopoulos C. Managing change, creativity and innovation. Sage; 2014 Jan 7.

36 Selznick P. Institutionalism "old" and "new". Adm Sci Q. 1996 Jun 1;41(2):270-7.

37 Reddy LK, Shammari FA. Six sigma approach on discharge process turnaround time in King Khalid Hospital, Hail, Saudi Arabia. Aust J Basic Appl Sci. 2013;7(14):523-33.

38 Tosi HL Jr, Slocum JW Jr. Contingency theory: some suggested directions. J Manag. 1984 Apr;10(1):9-26.

39 Al Khamis AA. Framing health policy in the context of Saudi Arabia. J Infect Public Health. 2016 Jan 1;9(1):3-6.

40 DiMaggio PJ, Powell WW. The iron cage revisited: institutional isomorphism and collective rationality in organizational fields. Am Sociol Rev. 1983 Apr 1;48(2):147-60.
Sustainability of Quality Improvement Initiatives within the Saudi MOH
Saudi J Health Syst Res 2021;1:3-10 DOI: $10.1159 / 000514179$ 
41 Scott WR. Institutional theory: contributing to a theoretical research program. Great minds in management: the process of theory development. 2005. p. 460-84.

42 Alkhamis A, Hassan A, Cosgrove P. Financing healthcare in Gulf Cooperation Council countries: a focus on Saudi Arabia. Int J Health Plann Manage. 2014 Jan;29(1):e6482.

43 Hassanain M, Zamakhshary M, Farhat G, AlBadr A. Use of Lean methodology to improve operating room efficiency in hospitals across the Kingdom of Saudi Arabia. Int J Health Plann Manage. 2017 Apr;32(2):133-46.

44 General Authority for Statistics [Internet]. Stats.gov.sa. 2019 [cited 2019 Jun 11]. Available from: https://www.stats.gov.sa/en/4025.

45 World Health Organisation [Internet]. who. int/iris. 2017 [cited 2019 Jun 25]. Available from: https://apps.who.int/iris/bitstream/ handle/10665/136842/ccsbrief_sau_en. pdf?sequence $=1$.

46 Mousa W, Aldehayyat JS. Regional efficiency of healthcare services in Saudi Arabia. Middle East Dev J. 2018 Jan 2;10(1):152-74.

47 The Australian Council on Healthcare Standards [Internet]. 2019 [cited 2019 May 29]. Available from: https://www.achs.org.au/.
48 Accreditation Canada [Internet]. Accreditation Canada. 2019 [cited 2019 Jun 11]. Available from: https://accreditation.ca/intl-en/ faq/.

49 Alkhenizan A, Shaw C. Impact of accreditation on the quality of healthcare services: a systematic review of the literature. Ann Saudi Med. 2011 Jul;31(4):407-16.

50 Alasmari A. Measurement of healthcare quality: a mixed-methods comparative study of accredited and non-accredited hospitals in Saudi Arabia (Doctoral dissertation, University of Salford).

51 UK Akkreditering Forum Limited [Internet]. Ukaf.org.uk. 2019 [cited 2019 Jun 11]. Available from: http://www.ukaf.org.uk/about. aspx.

52 Leopkey B, Parent MM. The (Neo) institutionalization of legacy and its sustainable governance within the Olympic Movement. Eur Sport Manag Q. 2012 Dec 1;12(5):437-55.

53 Kondra AZ, Hinings CR. Organizational diversity and change in institutional theory. Organ Stud. 1998 Sep;19(5):743-67.

54 Seddon J. Systems thinking in the public sector: the failure of the reform regime and a manifesto for a better way. Triarchy Press Limited; 2008.
55 McDonald KM. Considering context in quality improvement interventions and implementation: concepts, frameworks, and application. Acad Pediatr. 2013 Nov 1;13(6 Suppl): S45-53.

56 Øvretveit J. Total quality management in European healthcare. Int J Health Care Qual Assur. 2000 Apr 1;13(2):74-80.

57 Kannampallil TG, Schauer GF, Cohen T, Patel VL. Considering complexity in healthcare systems. J Biomed Inform. 2011 Dec 1;44(6): 943-7.

58 Robert G, Fulop N. The role of context in successful improvement. Perspectives on context. A selection of essays considering the role of context in successful quality improvement. London: Health Foundation; 2014. p. 31.

59 Batalden PB, Davidoff F. What is "quality improvement" and how can it transform healthcare? Qual Saf Health Care. 2007;16(1):2-3.

$60 \emptyset$ vretveit J. Understanding the conditions for improvement: research to discover which context influences affect improvement success [Internet]. BMJ quality \& safety. BMJ Group; 2011 [2019 Jun 25]. Available from: https://www.ncbi.nlm.nih.gov/pmc/articles/ PMC3066695/. 